\title{
Thinking with Doors and Perspectives: Reimagining Early Childhood Spaces
}

\author{
Sherry Rose, Kim Stewart, Pamela Malins, and Candace Gallagher
}

Sherry Rose is an associate professor with the Faculty of Education at University of New Brunswick (UNB). She has been teaching and learning early childhood pedagogies for 36 years across childcare, public school, and university settings. Email: srose@unb.ca

Kim Stewart is an assistant professor in the UNB Faculty of Education. She has experience in the field of education as a teacher (both locally and internationally), principal, researcher, curriculum developer, and literacy subject coordinator. Kim's research investigates multiple ways of being literate across institutional and community spaces with a focus on strong literate identities. Her current research investigates the educational pathways of early childhood educators in Eastern Canada. Kim can be reached at stewart@unb. $\underline{\mathrm{ca}}$

Pamela Malins is an assistant professor in the UNB Faculty of Education. She is interested in early childhood curriculum, literacies, and identities and the meaning-making opportunities afforded to young children to explore gender and sexual identities, specifically. Current research includes engaging community in conversations about comfort levels with various picture books that address gender and sexual identities. Previous research has included a SSHRC-funded critical discourse analysis of Canadian kindergarten curricula.

Email: Pamela.Malins@unb.ca

Candace Gallagher is a PhD candidate in the UNB Faculty of Education and coordinator for the Bachelor of Education in Early Childhood. Candace has experience teaching in early childhood settings, public school systems, and as an instructor at UNB. She has taught and has experience as a curriculum developer both internationally and locally. As a critical feminist researcher, she is investigating early childhood leadership as world making through pedagogical documentation in the interest of social justice. Email: candacegallagher@unhca

This paper explores, through a posthumanist lens, child care as a communal responsibility, taking into account varied partial perspectives produced through human and more-than-human intra-actions. Multiple narratives illustrate embodied and experienced complexities within child care spaces allowing us to reflect on uncomfortable truths to enact affirmative ethics as a way to transform the ways we care for children, their families, each other, and the spaces of child care. Specifically, we think with actual and virtual doors as producers and enablers to create spaces where early childhood educators might collaboratively interrogate how materiality and socially constructed hierarchies are embedded in the inequities that separate us, inequities further exposed and exacerbated by the COVID-19 pandemic.

Key words: child care; relational; perspective-taking; flexibility; equity

It is always about more than doors. (Palmer, 2019, p. 156)

Rosi Braidotti (2020) writes: "The current crisis can make us more intelligent about what we are ceasing to be and who we are capable of becoming" (p. 467). One way to reimagine our becoming is to think about problems as not just our own. Using the lens of posthumanism, we wonder how leaders might collectively respond to human and more-than-human entanglements in ways that do not pathologize the individual. What positionalities, relationships, and meanings might be possible when we withhold judgment? How might we listen and learn about the a/effects as we navigate our shifting realities? In the same way Veronica Pacini-Ketchabaw (2012) writes that "the clock, as both producer and enabler, affords possibilities and exclusions for practice" (p. 159), in this paper we are inviting the possibility of doors as producers and enablers that can provide opportunities to reimagine ways of caring within childcare systems in Canada. We draw on Pacini-Ketchabaw's (2012) words and 
insert the word doors instead of clocks to invite further reflection, so that we "may begin to understand human and non-human others-specifically here, children, educators, and [doors] - as coming into being through their relationships with each other" (p. 155). Thinking of doors "as assemblages [of] educators, [doors] and other nonhuman bodies intermingling in the classroom" (p. 156), we can move beyond thinking of doors as established boundary markers constructing spaces of privacy, safety, and/or freedom to see doors and their frames as spaces of embodied relational encounters. Encounters affect us, inspire questions, cause us to think and feel, and provoke varied relationalities. They invite us to act, turning toward or away from encounters, prompting us to ask questions of ourselves, our institutions, and our institutionally shaped pedagogies with the goal of imagining otherwise. All encounters are entangled relationalities, calling up the potential of possibilities if we are able to refuse the logic of Western binaries and detach ourselves from hierarchical relations (Braidotti, 2020). What does it mean to think with doors as a way to reimagine child care? Thinking with doors, this paper narrates daily complexities within child care spaces, allowing us to confront and change habitual ways of being as a way to transform caring for/with children, families, and each other.

The goal to reimagine child care is a lofty one, addressing ethics, relationality, and connectivity while questioning exclusions. Posthumanism invites reflection on the use of the communal "we." Rosi Braidotti (2020), reflecting on COVID circumstances, asks "who 'we' might be to begin with and whose anxiety is taking centre-stage in public debates about the crisis" (p. 467). Recognizing that we "...-are-not-one-and-the-same-but-are-in-thisconvergence-together” (p. 469), can we bring feminist, Indigenous, antiracist, and critical disabilities knowledges and ethics together and acknowledge that responses to current challenges are a communal rather than an individual responsibility? Braidotti suggests that the shift in perspective which COVID has produced "points in a different direction, towards some other middle-ground, another milieu, which expressed the awareness that 'we'-all living entities - share the same planetary home' (p. 467, italics in original). COVID has made it clear that supporting our child care educators and programs directly supports our families, our communities, our economies, our workplaces, our well-being, and the well-being of our shared world. How might time and space be constructed with a communal disposition that allows different kinds of perspective taking and relationships to occur? What follows are various perspectives revealed through thinking with doors that provoke possibilities for hearing the perspectives of a mother, a director, and an educator while thinking about belonging, "power rifts," and "webs of ever-shifting relationalities" (Braidotti, 2020, p. 467) and considering actual and virtual doors, including the doors of educational hierarchies. Each narrative enacts entanglements of clocks-doors-spaceschildren-families-educators-power.

\section{A mothers' perspective}

Time is not a line but a dimension, like the dimension of space.... You don't look back along time but down through it, like water. Sometimes this comes to the surface, sometimes that, sometimes nothing. Nothing goes away. (Atwood, 1988, p. 3)

When I think back, I remember rushing and watching my watch. Drop-off and pick-up were the worst times of the day. In June, on Jack's last day at the children's centre, I removed the watch from my wrist, and still today, my heartmindbody (Stewart, 2020) won't allow the watch's return.

Jack functions via his internal schedule. Everything is completed in his time, at his speed. At four years old, his way of being with the world didn't mix well with my mothering pace of negotiating job responsibilities and morning/afternoon drop-off and pick-up of two children at two locations.

Each day the routine was the same: Drop Sam off at school for 7:45 a.m.; next, Jack and I arrive in the parking lot 
for 7:55. By the time Jack and I walk through the doors of the children's centre at 8:00, the doors will be open. "Mommy, why am I the only kid here again today? I don't like being the only kid in the classroom."

My internal voice calls forward a continuous tension: Because I am balancing my mothering with my school district responsibilities, which begin at 8:30.

Every day, watching Jack remove his outerwear, I try to be patient. If I begin a conversation, he will stop everything and talk with me. In less timed circumstances, that is exactly what I would hope for with him. I glance at my watch. It is already 8:03 and I have a meeting at 8:30. My fingers are crossed, hoping the three traffic lights will be green today.

Jack doesn't have his boots off yet. To speed up the process, I reach down to pull off one boot, causing him to lose his balance and fall backwards, hitting his head on the floor. The sound of the crack was heard through the half-opened door of the classroom, causing one educator to open the door and enter the hallway. The intensity of this embodied experience (experienced by Jack, me, and the educator) cannot be measured by the clock (PaciniKetchabaw, 2012).

\section{A director's perspective}

The challenge is both to understand the ways in which clocks [or doors] are embedded in our practices and how they resonate with educators, children and families, and to imagine ways to rearrange these reverberations. (Pacini-Ketchabaw, 2012, p. 159)

For a long time, I read the closed door of the child care centre as an intentional exclusion of the children's families when they arrived to drop off their children. While I read the exclusion as intentional, the educators in the space at the time read the closed door as a protection of their planning and preparation time. In a fast-paced day, the closed door protects a quiet, collaborative space for the educators to fill paint pots, set out invitational materials, reflect on the previous day, and complete required paperwork before the children and their families flood the space.

Oftentimes a mom who was rushing between home, child care drop-off, and eventually work would be waiting in the hall for the exact timing of the open door. Drop-off and pick-up times required many hands as families negotiated their schedule demands while transitioning their children from the centre.

Over the years, various parents would make the request to drop off 15 minutes earlier or pick up 15 minutes later. Educators too made requests. They requested implementing a fine for early drop-off or pick-up when parents could not make the designated times. Despite raising the parent perspective, this long-time practice of keeping the doors closed until 8:00 a.m. was difficult to disrupt until an intersection of forces energized the possibility for change. Out of necessity, an educator had to bring her own child to the classroom. Was it fair to privilege her with access while denying early drop-off to parents? Another educator, who had previously worked at another centre, was empathetic to the drop-off and pick-up challenges that parents might experience on any given day and was willing to welcome early arrivals into the space. Eventually the decision was made to keep the doors open as a way to welcome families 15 minutes earlier.

\section{An educator's perspective}

What forms of knowledge are being produced? How are they connected to power? What opportunities are created for living together differently? (Braidotti, 2019, 00.20) 
Alec (a pseudonym) was in the middle of the classroom throwing toys on the floor, emptying every basket and bucket he could reach, angry he didn't have the flavour of yogurt he wanted for snack-a typical afternoon occurrence in the classroom since the 4-year-old had joined a month before. Reminding myself to stay calm, I walked toward him, but this time, instead of ignoring me, he ran across the room to a side door, pushed through, and closed the door behind him.

I knocked on the door and asked Alec to come out, making great effort to steady my voice. On the other side of the door was a small stairwell to the playground, and I feared he would get beyond the fenced-in playground to the busy highway.

Alec ignored my knocking. I pushed on the door to open it and realized he had barricaded himself on the other side. He was able to lie on his back, put his hands on the wall and his feet on the door. I stopped pushing and realized he had stopped yelling, and we both became calmer. I understand no. I picked up the bottle of cleaner and a cloth to occupy my body while my mind and eyes were with the child behind the closed door.

After a few moments that felt like an eternity, the door opened. Alec moved just to the other side of the door, once again back in the classroom. I looked to the co-educator with me in the room and exchanged what felt like an understanding to leave space for Alec to join the group when he was ready. I continued to clean tables. She moved to the book corner to read with children there.

Over the next few days, Alec would run to the stairwell and barricade himself on the other side, and when he was ready, he rejoined the group. We began to realize his need for space when his emotions became too much, and we wanted to find peace between his need and our need to ensure he was safe. On the fourth day, after the children had gone home, we found a drill, took the door off its hinges, and tucked it away in the storage room.

No one asked about the door the next day. Children walked to the empty door frame, looked in the stairwell at the steps they used to get to the playground, and walked away. That afternoon when Alec needed time and space, he ran to the stairwell and sat on the bottom step where we could see him-Alec had a place to go/be within our classroom. Over the next few weeks, when Alec became overwhelmed, angry, or frustrated, he would sit on that bottom step. The positives we saw and felt were not seen by the director, who told us to put the door back: "If Alec can't be within the classroom, then he has to go home."

\section{Opening the doors of educational hierarchy}

The doors of education are well known to have established barriers in our society. There are numerous misalignments in our postsecondary system where there is a failure to credit lived experiences, self-study, nondegree university courses, and community college programs. Many early childhood educators find themselves unable to pursue additional educational opportunities to advance their careers due to the responsibilities of working full time while parenting young children or caring for seniors, and they experience institutional classed boundaries or educational streaming. In response to these challenges, members of the Early Childhood Centre at the University of New Brunswick (UNB; n.d.) collaborated with community leaders to create an online Bachelor of Education degree (BEd) in early childhood education (ECE) - the first degree program of its kind in Canada-offering a BEd and a New Brunswick Certificate IV teacher's licence. Opening doors online offers flexibility while acknowledging the many preexisting responsibilities in early childhood educators' lives, including their jobs, parental roles, care for elders, and increasing responsibilities due to COVID. 
Early childhood educators often talk about the opening provided by this online degree as they learn about and enroll in the program. As one early childhood educator shared, "I am a working professional and mum to three busy kids!" A bachelor of education degree in early childhood education honours a range of personal desires, such as deepening their knowledge and their leadership and pedagogical capacities to support educators and/or directors in child care, becoming a licensed teacher, or simply achieving a university degree. One early childhood educator told us the program was "like a dream come true" and another said, "It feels a lot like a "too good to be true' opportunity." These individuals shared narratives that reinforced the social inequalities that permeate society creating hierarchies among those involved in the education and care of young children. As one early childhood educator commented, "This course has allowed me to follow my dream of an ECE degree and the professors have worked hard to make it possible for us to balance with our home and work responsibilities." Another noted, "It is exactly what I always wanted: an online course that extends my early childhood education diploma and allows me to become a certified teacher. It is the perfect program for a single parent who is working full time."

Upon completion of the degree, early childhood educators have the choice of teaching in early childhood centres and/or the public school system (kindergarten to grade 3). Being an early childhood educator in a school represents a significant increase in wages, benefits, working conditions, resource budgets, and access to paid professional learning opportunities (Cannella, 2002; Moss, 2006; Osgood, 2004). UNB's BEd in ECE degree may play a significant role in recognizing that early childhood educators are not all equally located, opening institutional doors. However, the danger is always about reinscribing a hierarchy of a different kind when there is a collective failure to create more equitable economic systems.

\section{Virtual doors and COVID}

The development and planning of UNB's BEd in ECE degree program, in progress for the past five years, intentionally responded to the lived realities of early childhood educators by offering the flexibility of online delivery, which is aligned with the virtual circumstances created by the COVID-19 pandemic. Early childhood educators made the decision to enroll in the new online degree program while provinces were declaring states of emergency and issuing quarantine measures. The social inequities that surround the child care sector have only become amplified during this time. Some early childhood educators were able to shift from part-time to full-time enrollment, while others had to take a break from the program to find piecemeal employment, and others were required to put in extra time running their centres as they accommodated other families and spent time cleaning facilities. Yet, early childhood educators are crucial to a functioning economy, enabling other workers to be freed of their own child care responsibilities.

COVID has also created opportunities for UNB's early childhood team to schedule weekly virtual meetings to discuss how the materials, spaces, and individuals in the program would interact. Together we coauthored instructor, early childhood educator, and practicum handbooks to support the community of early childhood educators and instructors. Virtual gatherings were held to bring university instructors and early childhood educators together across multiple provinces and schedules. Our goal was to maintain an affirmative ethical responsibility to educators' lived private and public responsibilities entangled with their desire to learn.

COVID has magnified the complexities of care. We are forced to consider early childhood in relation with the ecological world, seeing child care and employment as intertwined, and engaging with community and families in unison. The need to recognize early childhood educators as caregivers in both public and private spheres is paramount. As more individuals walk back through the physical doors of workspaces, funds are needed 
to support early childhood centres, cover wages, and provide flexibility, such as wraparound services that accommodate early and late drop-off and pick-up. Early childhood educators require equitable recognition for their education and the care they provide, both as an essential part of the fabric of a functioning economy and, more importantly, as a necessary support for the flourishing of our common world.

\section{Challenges and possibilities of reconceptualization}

Despite the many benefits of UNB's BEd in ECE program, tensions arose in implementing the degree, such as negotiating university structures, addressing the potential depletion of early childhood systems, drawing learners from other postsecondary programs, designing practicum experiences that respect early childhood pedagogies and accommodate employment, and determining whether early childhood education and care should be linked to public education and how this dynamic might disrupt education as usual. The articulated challenges speak to the need to shift our thinking and institutional practices to reimagine other possible landscapes for child care and education that disrupt hierarchies and the binary of open or closed doors. This paper thinks with door entanglements to critique our embodied and experienced complexities.

The narratives we have presented offer perspectives that require courageous conversations, fearless listening, and a willingness to make fluid adjustments. While these are not unfamiliar dispositions to many early childhood educators, they are amplified by COVID. A practice of critical self-knowledge that embraces relationalities of human and more-than-human becomings and enacts affirmative ethics is necessary for disrupting inequities. In this paper we think with actual and virtual doors as producers and enablers to create spaces where early childhood educators might collaboratively interrogate how materiality and socially constructed hierarchies are embedded in the differences that separate us (Braidotti, 2020). We challenge binaries such as "with me or against me," imagining expansive relationships, multiple perspectives, and responsibilities that enact connections across systems and communities and through doors to disrupt the oppression of early childhood educators, children, and families. 


\section{References}

Atwood, M. (1988). Cat's eye. McClelland \& Stewart.

Braidotti, R. (2019, April 2). Revolution is a fascist concept [Video]. https://www.youtube.com/watch?v=A6PLJqtDp6Q

Braidotti, R. (2020). "We" are in this together, but we are not one and the same. Bioethical Inquiry, 17, 465-469. https://doi.org/10.1007/ $\underline{\text { s11673-020-10017-8 }}$

Cannella, G. S. (2002). Deconstructing early childhood education: Social justice \& revolution. Peter Lang.

Moss, P. (2006). Structures, understandings and discourses: Possibilities for re-envisioning the early childhood worker. Contemporary Issues in Early Childhood, 7(1), 30-41.https://doi.org/10.2304ciec.2006.7.1.30

Osgood, J. (2004). Time to get down to business?: The responses of early practitioners to entrepreneurial approaches to professionalism. Journal of Early Childhood Research, 2(1), 5-24. https://doi.org/10.1177/1476718X0421001

Pacini-Ketchabaw, V. (2012). Acting with the clock: Clocking practices in early childhood. Contemporary Issues in Early Childhood. 13(2), 154-160. https://doi.org/10.2304ciec.2012.13.2.154

Palmer, D. P. (2019). Falling for myself: A memoir. Wolsak \& Wynn.

Stewart, K. (2020). Sacred encounters: Literacy beyond cardboard words (Doctoral dissertation, University of New Brunswick). UNB Libraries Scholar Research Repository. https://unbscholar.lib.unb.ca/islandora/object/unbscholar\%3A10437

University of New Brunswick. (n.d.). BEd in early childhood education. https://www.unb.ca/fredericton/education/undergrad/early.html 